\title{
Governance, Innovation, Profitability, and Credit Risk: Evidence from Italian manufacturing firms
}

\author{
Alessandra Amendola \\ Vincenzo Candila \\ Giuseppe Storti \\ Department of Economics and Statistics (DISES) \\ Luca Sensini \\ Department of Management and Innovation System (DISA/MIS) \\ University of Salerno, Italy \\ Via Giovanni Paolo II \\ $132-84084$ Fisciano (SA)
}

\begin{abstract}
The research focuses attention on companies in the chemical-plastic sector, investigating corporate governance, investment and financing decisions, innovation, profitability, and credit risk. The investigation method used is mixed. The data and information were extracted from official databases and from a structured questionnaire. The stratified random method was used for sampling. 178 firms are included in the sample. The results show a prevalence of companies owned by a single person or a limited number of shareholders (in some cases of the same family), where the owners centralize decision-making power. Companies have a strong propensity to invest in innovation. Investments are mainly financed by self-financing or equity capital. The analysis of the causal relationships highlights further significant aspects relating to credit risk, profitability and innovation.
\end{abstract}

Keywords: Governance, Investment, Performance, Credit Risk, Innovation

\section{Introduction}

The research focuses attention on companies in the chemical-plastic sector, investigating corporate governance, investment and financing decisions, innovation, profitability, and credit risk. In this regard, theoretical literature and empirical findings have shown that the classification of the sector could be a relevant factor in order to avoid and control possible anomalies (Hall et al., 2000; Sensini, 2017). The companies analyzed are based in the province of Salerno, in Italy. In some cases, the research required a lot of data and information not available from the traditional sources used for this type of analysis. Therefore, we used a mixed investigation method, structured as shown below. In the first phase, we collected all the information available from official sources such as the Chamber of Commerce and the Revenue Agency (local ministerial tax office). The analysis of the data revealed anomalies between the same data present in the two archives. Therefore, we proceeded to eliminate all the anomalies (e.g. inactive companies, transferred, bankrupt companies, etc.) and we have identified a new universe of active companies operating in the chemical-plastic sector. Once all the active companies were identified, we proceeded to select the sample.

In line with the literature (Cicchitelli et al, 1997; Cochran, 1977), sampling was performed with a stratified random method. This approach made it possible to improve the efficiency of the estimates and ensure the representativeness of the sample. Once the sample was defined, we prepared a structured questionnaire to obtain all the relevant information that was not available in the database of the Chamber of Commerce and the Revenue Agency. Considering the objectives of the research and the investigation approaches suggested by the literature (Porter, 
1980; 1985; Coda, 1992), the questionnaire was aimed at gathering information on the main structural and functional characteristics of companies in the chemical - plastic sector.

Governance, ownership, management, relations with financial intermediaries, innovation and other variables of interest were examined in - depth with the questionnaire. The total number of questions was 166. Many of them included multiple answers. Information on the selected sample units was collected using the face-to-face interview. The application of this method has enabled higher response rates and at the same time an increase in the level of significance of the responses. To avoid distortions, the interviewers were properly trained (Brasini et al. 2002; Bradburn et al., 2004). The questionnaire was designed and implemented with the SurveyMonkey program. Finally, the information obtained from the questionnaires was integrated with that of the databases of the Chamber of Commerce and the Revenue Agency.

The paper is divided into 5 sections and is organized as follows. Section 2 illustrates the dataset and the sample design. The next section describes the main characteristics of the companies in the sample, focusing on the aspects of interest. Section 4 analyzes the relationship between investment, innovation, profitability, and credit risk. Section 5 gives some concluding remarks.

\section{Data Set and Sample Design}

The data set include structural and economic characteristics of $n=178$ sample firms active in the chemical-plastic sector based in the province of Salerno, in Italy. The research was carried out involving primary and secondary sources regarding the active firms in the ATECO sectors C20 and C22 (chemic-plastic). First-hand information was collected via a structured questionnaire designed administered to a random sample opportunely selected by the sampling frame provided by the Chamber of Commerce and Revenue Agency (local ministerial tax office) for a total population of $\mathrm{N}=401$ units. The availability of demographical and economic information for each firm in the populations has to lead to the possibility of including stratification variables in the sample designed. Stratification sampling allows to preliminary divide of the population sub-groups or strata according to a selected criterion in order to reduce the variability in each stratum and increase the efficiency of the estimation procedure (Cicchitelli et al, 1997; Cochran, 1977). A double stratification was computed in the sample design considering the geographical location of each firm within the area of interest and the economic weights expressed in terms of turnover. The first geographical criterion has allowed dividing the area of interest in 4 sub-area according to the structural characteristics provided by the Chamber of Commerce. Moreover, a second stratification was related to the size of the firms (small, medium and large) considered in terms of the level of turnovers as provided by the Revenue Agency.

The overall sample size, $n=178$, has been calculating, assuming the estimation of a proportion $\mathrm{p}$, following the equation:

$$
n=\frac{n_{0}}{1+\frac{n_{0}}{N}}
$$

Where $\mathrm{N}$ is the population size and $n_{0}$ is given by:

$$
n_{o}=\frac{z^{2}(0.975) p(1-p)}{\varepsilon^{2}} .
$$


The level of $\mathrm{p}$ has been fixed assuming a maximum level for the variability of any hypothetical dichotomous variable, reached for $p=0.5$. The sample error has been set as $|\varepsilon| \leqslant 0.05$ with a probability $1-\alpha=0.095$.

\section{Business characteristics}

This section highlights the main results highlighted by the analysis of the characteristics of the companies in the sample. The results are organized as follows. The first part analyzes the characteristics of companies with reference to ownership, governance, profitability and critical success factors. This perspective is important because it affects the managerial and operational characteristics of companies (Jensen and Meckling, 1973; Fama and Jensen, 1983). The second part describes the results relating to the dynamics of investments and loans. Attention is also focused on research and development activities, because of their importance for the company's competitive strategy (Helfert, 2000). Likewise, funding methods are important for understanding how many and what resources (owner and/or lender) they use to finance investments. Finally, the third part highlights the results relating to the labor dynamics.

\subsection{Size, Corporate Governance, Profitability, and Critical Success Factors}

Table 1 highlights the size of the sample companies. Size is determined in agreement with the definition of SMEs given in European Commission recommendation 2003/361/EC of 6 May 2003.

Tab. 1 - Size

\begin{tabular}{ll}
\hline Size & \\
\hline Microenterprises & $61,9 \%$ \\
Small Firms & $20,1 \%$ \\
Medium Firms & $13,8 \%$ \\
Larger Firms & $4,2 \%$ \\
\hline
\end{tabular}

As evident, the sector is characterized by a large presence of microenterprises $(61,9 \%)$ and small firms $(20,1 \%)$. However, in the sector, there are also some large companies $(4,1 \%)$ active both on EU and international markets.

Table 2 shows the main results with respect to the following variables of interest: ownership, corporate governance, and performance.

Tab. 2 - Ownership, Corporate Governance, Profitability and CSF

\begin{tabular}{ll}
\hline Founder of the Company & \\
\hline Current owner & $69,0 \%$ \\
Parents of the current owner & $15,0 \%$ \\
Current owner group & $5,0 \%$ \\
Grandparents of the current owner & $4,9 \%$ \\
Other answers & $6,1 \%$ \\
\hline Company Members/Shareholders & \\
\hline 1 & $8,7 \%$ \\
2 & $41,3 \%$ \\
$3-5$ & $45,7 \%$ \\
6 or more & $4,3 \%$ \\
\hline Stakeholders involved in the decision-making process & $70,6 \%$ \\
\hline Company Members/Shareholders & $20,0 \%$ \\
Company Members/Shareholders and Family & $5,0 \%$ \\
Trade Organizations & $4,4 \%$ \\
Business Consultants/Chartered accountant & $78,6 \%$
\end{tabular}




\begin{tabular}{ll}
2008 & $74,0 \%$ \\
2009 & $67,1 \%$ \\
2010 & $66,9 \%$ \\
\hline Critical success factors (more than one answer) & \\
\hline Products quality & $47,3 \%$ \\
Value for money & $40,2 \%$ \\
Specialization level & $33,4 \%$ \\
Punctuality of deliveries & $32,1 \%$ \\
Flexibility & $28,2 \%$ \\
\hline
\end{tabular}

In most cases (69\%), businesses were founded by the current owner and are made up of multiple partners (97\%). The presence of companies with more than 6 shareholders or widespread shareholding is minimal. Second and third-generation enterprises are significant (19,9\%) but still less than that found in other sectors (Amendola et al., 2013). The concentration of ownership affects the strategic and operational behaviour of the company, as evidenced by the literature (Demsetz and Lehn, 1985; Westhead and Howorth, 2006; McConnell and Servaes, 1990, Pedersen and Thomsen, 1997).

In terms of governance, the entrepreneur and/or owners define the strategy of the company and make the decisions deemed relevant for the survival and development of the company. In some cases, trade organizations (5\%) and the chartered accountant $(4,4 \%)$ are involved in the decision making-process. In family businesses, the decision-making process involves entrepreneurs and all family members. Given the size of the companies, the data confirm the results highlighted by the extensive literature on the theme of SMEs (Marchini, 1995).

Finally, quality and price represent a fundamental element to compete on the market.

\subsection{Investments and Financing}

Table 3 summarizes the percentage frequency distributions for the main variables analysed.

Tab. 3 - Investments and Research and Development Activities

\begin{tabular}{ll}
\hline Average use of the plants & \\
\hline $30,0-50,0 \%$ & $21,3 \%$ \\
$50,1-60,0 \%$ & $4,3 \%$ \\
$60,1-70,0 \%$ & $6,4 \%$ \\
$70,1-80,0 \%$ & $14,9 \%$ \\
$80,1-90,0 \%$ & $17,0 \%$ \\
$>90,0 \%$ & $36,2 \%$ \\
\hline Investments made in the last 4 years & \\
\hline Yes & $81 \%$ \\
Not & $19 \%$ \\
\hline Type of investments & $57,9 \%$ \\
\hline Plant, machinery and equipment & $29,8 \%$ \\
Research and development & $22,8 \%$ \\
Infrastructure & $19,3 \%$ \\
Business information systems and intangible assets & $12,3 \%$ \\
Vehicles and Trucks & $7,0 \%$ \\
Logistic & $8,8 \%$ \\
Others & \\
\hline Purpose of investments & $37,1 \%$ \\
\hline Increase in product lines
\end{tabular}




\begin{tabular}{ll} 
Increase in production capacity & $30,2 \%$ \\
Market share increase / Entry into new markets & $22,7 \%$ \\
Reduction in labor costs & $19,1 \%$ \\
Adaptation to regulations & $18,9 \%$ \\
Energy saving & $14,2 \%$ \\
Others & $1,8 \%$ \\
\hline Innovation & $70,4 \%$ \\
\hline Product innovations & $51,8 \%$ \\
Process innovations & $19,0 \%$ \\
Organizational or managerial innovations & $33,3 \%$ \\
\hline Factors driving innovations & $28,1 \%$ \\
\hline Internal know-how and resources & $28,1 \%$ \\
Suppliers & $26,3 \%$ \\
Customer requests & $7,0 \%$ \\
Sources of information (conferences, trade magazines, etc.) & $7,0 \%$ \\
Competitors & $8,8 \%$ \\
\hline Universities and research centers & \\
Others &
\end{tabular}

The data show a particularly high percentage of the use of the plants. $36.2 \%$ of companies use production capacity almost fully (> 90.0\%) and $68.1 \%$ of companies use more than $70 \%$ of production capacity. The prevalence of companies $(81 \%)$ has made investments in the past 4 years. The most significant investments were in Plant, machinery and equipment. An important share of investments also involved Research and development(29,8\%) and Infrastructure $(22,8 \%)$. The investments were aimed at increasing product lines $(37,1 \%)$, production capacity $(30,2 \%)$, and market share $(22,7 \%)$. Investments also made it possible to reduce labor costs. The innovation processes mainly concerned about the creation of new products $(70,4 \%)$. However, significant process innovations $(51,8 \%)$ and innovations to the corporate organizational and information system (19\%) were also introduced. Innovation processes are mainly produced internally $(33,3 \%)$. However, suppliers $(28,1 \%)$ and customers $(28,1 \%)$ also have a strong driving role in promoting innovation processes. In this regard, the relevance of universities and research centres is low $(7,0 \%)$.

Table 4 shows the financing behavior of the firms and the critical issues found in the relationship between businesses and the banking system.

Tab. 4 - Financing

\begin{tabular}{lc}
\hline Method of financing investments & \\
\hline Self-financing and capital increase subscribed by the current owners & $72.0 \%$ \\
Bank loans & $26.1 \%$ \\
Public contributions & $1.9 \%$ \\
\hline Critical issues in the relationship with the banking system & \\
\hline Collateral required & $32.6 \%$ \\
Overall costs & $23.3 \%$ \\
Excessively long delivery times & $18.6 \%$ \\
Accounting documentation required & $16.3 \%$ \\
None & $9.3 \%$ \\
\hline Degree of difficulty for bank loans & \\
\hline High & $21,9 \%$ \\
Medium & $50,5 \%$
\end{tabular}


Low

\begin{tabular}{ll}
\hline Number of banking relationships & \\
\hline $1-2$ Banks & $53,5 \%$ \\
$3-5$ Banks & $35.7 \%$ \\
$6-10$ Banks & $8.9 \%$ \\
$>10$ Banks & $1,9 \%$ \\
\hline
\end{tabular}

The data show that the investments are mainly financed by reinvested profits and capital contributed by the shareholders $(72 \%)$. The remaining part is financed by bank loans $(26,1 \%)$ and, minimally, by public contributions $(1,9 \%)$. Most of the companies have registered medium-high $(72,4 \%)$ criticalities in the relationship with the banking system. In particular, the guarantees required $(32,6 \%)$, the overall costs $(23,3 \%)$ and the time required to obtain the loan $(18,6 \%)$ represent the most critical issues. Finally, most businesses have relationships with multiple banks.

The results highlight some specific features typical of SMEs. The difficulty of SMEs in finding adequate sources of financing from the banking system, which highlights the presence of financial constraints (Ricci and Colombini, 1987; Sanchez and Sensini, 2017). The tendency of SMEs to finance investments through the use of own resources (Myers, 1984; Myers and Majluf, 1984) due to the reluctance to the intervention of third parties in the capital. In fact, the intervention of new financing partners could lead to a limitation in the company's direction and control activity. Therefore, the close integration between ownership, control and management implies the subordination of investments to self-financing capacity.

\subsection{Labor dynamics}

Table 5 summarizes the main results relating to this section.

\section{Tab. 5-Labor dynamics}

\begin{tabular}{ll}
\hline Number of employees & \\
\hline 1 & $4,3 \%$ \\
$2-9$ & $39,1 \%$ \\
$10-25$ & $34,8 \%$ \\
$26-49$ & $15,2 \%$ \\
$>50$ & $6,6 \%$ \\
\hline Variation in the number of employees & \\
\hline None & $35,9 \%$ \\
Decrease $<10 \%$ & $25,6 \%$ \\
Decrease >10\% & $10,2 \%$ \\
Increase <10\% & $20,5 \%$ \\
Increase >10\% & $7,8 \%$ \\
\hline Impact of labor costs on production costs & \\
\hline $0-15 \%$ & $18,9 \%$ \\
$16-25 \%$ & $21,6 \%$ \\
$26-40 \%$ & $43,2 \%$ \\
$>40 \%$ & $16,3 \%$ \\
\hline Reasons for employee reduction & \\
\hline Turnover decrease & $71,4 \%$ \\
New Plants and Machinery & $7,1 \%$ \\
Increase in labor costs & $7,1 \%$ \\
Other & $14,4 \%$ \\
\hline
\end{tabular}


The number of employees remained constant $(35.9 \%)$ or recorded small increases $(20.51 \%)$ and/or decreases (25.64\%). The main reason for the reduction in employees is, in over $71 \%$ of cases, due to a reduction in turnover. The incidence of labor costs on total production costs is conditioned by the size of the company. The percentage weight of this cost is more contained in larger companies, with significant multi-year investments. Conversely, in micro and small businesses, the impact of labor costs is more significant.

\section{Investments, Innovation, Profitability and Insolvency Risks}

This section analyzes the relationships that link profitability, innovation and credit risk with the other explanatory variables of business management highlighted in the previous section. A total of 19 variables are used and are shown in table 6 .

Tab. 6 - Variables analyzed

\begin{tabular}{|c|c|c|}
\hline Variables & Description & Type \\
\hline var1 & CreditRisk class ( $1=$ highrisk) & Binary \\
\hline var2 & Dummy profitability (1 = Loss) & Binary \\
\hline var3 & Sector $(1=$ Food $)$ & Binary \\
\hline var4 & Agro Nocerino (1=true) & Binary \\
\hline var5 & Metropolitan Area (1=true) & Binary \\
\hline var6 & CilentoVallo di Diano (1=true) & Binary \\
\hline var7 & Legal Nature (1=capital company) & Binary \\
\hline var8 & Age & Discrete \\
\hline var9 & Turnover & Continous \\
\hline $\operatorname{var} 10$ & Average Exports (last 4 years) & Continous \\
\hline var11 & Age of the owner & Discrete \\
\hline $\operatorname{var} 12$ & Gender $(1=$ male $)$ & Binary \\
\hline $\operatorname{var13}$ & Owner Education Level (1= graduate) & Binary \\
\hline $\operatorname{var} 14$ & Partecipants in the decision making process ( 1 person) & Binary \\
\hline $\operatorname{var} 15$ & Average difficulty in accessing credit & Continous \\
\hline $\operatorname{var} 16$ & Average Labor Costs/Total Costs & Continous \\
\hline $\operatorname{var} 17$ & Percentages third party works & Continous \\
\hline $\operatorname{var} 18$ & Product or process innovations $(>1)$ & Binary \\
\hline var19 & Investments in the past 4 years $(>1)$ & Binary \\
\hline
\end{tabular}

The four variables (var1, var2, var18, var19) are used as dependent variables. The remaining variables instead were used as explanatory variables. Credit risk (var1) was measured on the basis of the risk classes identified by CERVED. The classes are formed as shown in table 7.

Tab. 7 - Risk Classes CERVED and Frequency in the Sample

\begin{tabular}{lrrr}
\hline Class & Description & Frequency & Relative Frequency. \\
\hline 0 & Updating & 0 & 0.131 \\
1 & High risk & 29 & 0.027 \\
2 & Medium risk & 6 & 0.023 \\
3 & Without insolvencies & 5 & 0.000 \\
4 & Low Risk & 164 & 0.742 \\
5 & Without monitoring & 0 & 0.000 \\
6 & Inactive & 4 & 0.018 \\
7 & With insolvencies - A & 0 & 0.000 \\
8 & With insolvencies- B & 13 & 0.059 \\
\hline
\end{tabular}

The variables indicated in the table have been aggregated into a binary variable that assumes the value 1 in case of high risk and 0 in case of low risk. Mode 0 corresponds to the low-risk classes of the Cerved classification. For 
greater clarity, variable 7 of table 7, "With insolvencies - A" indicates a company with insolvencies or bankruptcy procedures that could adversely affect the assessment of corporate reliability. Variable 8 of table 7 "With insolvencies - B" indicates a company with insolvencies or financial imbalances that do not necessarily have a negative impact on the assessment of the reliability of companies.

Variable 2 (profitability) assumes a value of 0 in the case of profit and a value of 1 in case of loss. Variable 18, relating to innovation, assumes a value of 1 in the case of process and / or product innovations and a value of 0 in the remaining cases. Variable 19, relating to investments, assumes a value of 1 if the company has made investments and a value of 0 in the absence of investments.

The analysis aims to identify investment probabilities, innovation, profitability and credit risk. Binary variables are used as dependent variables to achieve research goals. Using binary variables as employees do not allow you to use linear regression. Therefore, this study applies a logistic regression model. This model can take values from 0 to 1 and uses the following function (Dobson and Barnett, 2008; Hosmer and Lemeshow, 2000; McCullagh and Nelder, 1989).

Let $Y_{i}=\{0,1\}$ be a dichotomic variable that assumes the following Bernoulli distribution, conditioned to a set of covariates $X_{i j}$ with $\mathrm{j}=1, \ldots, \mathrm{p}$ and $\mathrm{i}=1, \ldots, \mathrm{n}$,

$$
\left(Y_{i} \mid X_{1, i}, \ldots, X_{p, i}\right) \sim B\left(1, \pi_{i}\right)
$$

where the conditional distribution function is given by:

$$
p\left(Y_{i} \mid X_{1, i}, \ldots, X_{p, i}\right)=\pi_{i}^{Y_{i}}\left(1-\pi_{i}\right)^{1-Y_{i}}
$$

and

$$
\pi_{i}=\frac{1}{1+e^{-\left(\beta_{0}+\sum_{j=1}^{p} \beta_{i} X_{i, j}\right)}}=\frac{1}{1+e^{-\mathbf{X}_{i}^{\prime} \beta}}
$$

with $X_{i}=\left(1, X_{1, i}, \ldots, X_{p, i}\right)^{\prime}$ and $\beta=\left(\beta_{0}, \beta_{1} \ldots, \beta_{p}\right)^{\prime}$ is a vector of regression parameters that can be estimated by means of maximum likelihood estimators (MLE).

In the event that the dependent variable is given by the dummy relating to the risk of credit (var1), the results of the estimates are shown in table 8 .

Tab 8 - Logistic regression var1 (credit risk): estimates $(\beta \mathbf{i})$ and $\mathbf{p}$-values $\left(\mathbf{p}\left(\boldsymbol{\beta}_{\mathbf{i}}\right)\right)$

\begin{tabular}{lrrrr}
\hline Variables & $\boldsymbol{\beta 0}$ & $\boldsymbol{\beta 1}$ & $\boldsymbol{p}(\boldsymbol{\beta 0})$ & $\boldsymbol{p}(\boldsymbol{\beta 1} \mathbf{)}$ \\
\hline var2 & -1.3863 & 0.1335 & 0.0131 & 0.8668 \\
var4 & -1.3863 & 0.2877 & 0.0024 & 0.7584 \\
var5 & -2.0369 & 1.7004 & 0.0009 & 0.0450 \\
var6 & -0.8109 & -18.7551 & 0.0563 & 0.9952 \\
var7 & -1.5041 & 0.2513 & 0.0544 & 0.7821 \\
var8 & -0.5589 & -0.0528 & 0.4465 & 0.2634 \\
var9 & -0.8022 & 0.0000 & 0.0956 & 0.2062 \\
var10 & -1.1858 & 0.0000 & 0.0036 & 0.5212 \\
var11 & -2.3447 & 0.0216 & 0.1402 & 0.4835 \\
var12 & 15.1333 & -16.3497 & 0.9947 & 0.9943 \\
var13 & -1.4816 & 0.6343 & 0.0028 & 0.4553 \\
var14 & -1.3863 & 0.2877 & 0.0056 & 0.7299 \\
var15 & -2.2808 & 0.4126 & 0.1007 & 0.3904 \\
var16 & -1.5002 & 0.0086 & 0.1361 & 0.7783 \\
var17 & -1.7929 & 0.0122 & 0.0059 & 0.1973
\end{tabular}




\begin{tabular}{rrrrr} 
var18 & -2.0794 & 1.0296 & 0.0499 & 0.3698 \\
var19 & -0.6931 & -0.7732 & 0.4235 & 0.4289 \\
\hline
\end{tabular}

The results show a different credit risk depending on the geographical area of reference. Companies in the metropolitan area have a much higher credit risk (0.417) than that of other areas.

In the case that the dependent variable is given by the profitability (var2), the results of the estimates are shown in table 9.

Tab. 9 - Logistic regression var 2 (profitability): estimates $(\beta i)$ and p-values $(p(\beta i))$

\begin{tabular}{lcccc}
\hline Variables & $\boldsymbol{\beta 0}$ & $\boldsymbol{\beta 1}$ & $\boldsymbol{p}(\boldsymbol{\beta 0})$ & $\boldsymbol{p}(\boldsymbol{\beta 1})$ \\
\hline var1 & -0.1335 & 0.1335 & 0.7152 & 0.8668 \\
var4 & -0.1335 & 0.1335 & 0.7152 & 0.8668 \\
var5 & -0.1542 & 0.1542 & 0.6952 & 0.8254 \\
var6 & 0.0000 & -0.3365 & 1.0000 & 0.6331 \\
var7 & 0.1823 & -0.4055 & 0.7633 & 0.5727 \\
var8 & -0.3157 & 0.0130 & 0.5929 & 0.6693 \\
var9 & 0.0807 & 0.0000 & 0.8445 & 0.3370 \\
var10 & -0.1340 & 0.0000 & 0.6954 & 0.7891 \\
var11 & 1.8165 & -0.0391 & 0.1826 & 0.1591 \\
var12 & -1.0368 & 0.8650 & 0.4590 & 0.4961 \\
var13 & 0.0741 & -0.9214 & 0.8474 & 0.2436 \\
var14 & -0.2412 & 0.5776 & 0.5495 & 0.4164 \\
var15 & 1.5119 & -0.6498 & 0.1722 & 0.1130 \\
var16 & -0.8032 & 0.0315 & 0.3909 & 0.3122 \\
var17 & 0.1343 & -0.0047 & 0.7746 & 0.5562 \\
var18 & 0.6931 & -1.0678 & 0.3270 & 0.1865 \\
var19 & 1.6094 & -1.9889 & 0.1418 & 0.0845 \\
\hline
\end{tabular}

The probability that a company ends the year with a loss is significantly lower if the company has made investments in the past 4 years, with a value of 0.406 compared to 0.833 if no investments have been made. Therefore, the data collected suggests that making investments can help prevent critical situations.

As regards innovation (var 18), the estimates and the related p-values have been reported in Table 10.

Tab. 10 - Logistic regression var18 (innovation): estimates $(\beta \mathbf{i})$ and $\mathbf{p}$-values $(\mathbf{p}(\boldsymbol{\beta} \mathbf{i}))$

\begin{tabular}{lrrrr}
\hline Variables & $\boldsymbol{\beta} \mathbf{0}$ & $\boldsymbol{\beta 1}$ & $\boldsymbol{p}(\boldsymbol{\beta 0})$ & $\boldsymbol{p}(\boldsymbol{\beta 1})$ \\
\hline var1 & 0.9163 & 1.0296 & 0.0285 & 0.3698 \\
var2 & 1.6740 & -1.0678 & 0.0078 & 0.1865 \\
var4 & 1.0986 & 0.0000 & 0.0118 & 1.0000 \\
var5 & 1.0986 & 0.0000 & 0.0198 & 1.0000 \\
var6 & 1.0986 & 0.0000 & 0.0198 & 1.0000 \\
var7 & 0.4055 & 1.0296 & 0.5299 & 0.2065 \\
var8 & 0.3144 & 0.0532 & 0.6599 & 0.2342 \\
var9 & 0.9467 & 0.0000 & 0.0447 & 0.6896 \\
var10 & 1.0934 & 0.0000 & 0.0070 & 0.9683 \\
var11 & 0.2183 & 0.0178 & 0.8829 & 0.5622 \\
var12 & 2.3573 & -1.1787 & 0.1479 & 0.4229 \\
var13 & 0.9985 & 0.2542 & 0.0239 & 0.7813 \\
var14 & 1.0415 & 0.0572 & 0.0283 & 0.9443 \\
var15 & 1.4253 & -0.0323 & 0.2643 & 0.9452 \\
var16 & 3.2075 & -0.0668 & 0.0157 & 0.0960 \\
$\operatorname{var17}$ & 1.2735 & -0.0014 & 0.0242 & 0.8836 \\
var19 & -0.4055 & 1.8326 & 0.6569 & 0.0723 \\
\hline
\end{tabular}

In addition to the dummy relating to investments with a probability of innovating that goes from 0.400 to 0.806 , the results also highlight the significance of the variable relating to the incidence of labor costs. In particular, the probability of innovating significantly decreases in the presence of a high incidence of labor costs (i.e. in 
companies with labor-intensive processes).

As regards investment (var 19), the estimates and the related p-values have been reported in Table 11.

Tab. 11 - Logistic regression var19 (investiments): estimates $(\beta i)$ e p-values $(p(\beta i))$.

\begin{tabular}{lrrrr}
\hline Variables & $\boldsymbol{\beta 0}$ & $\boldsymbol{\beta 1}$ & $\boldsymbol{p}(\boldsymbol{\beta 0})$ & $\boldsymbol{p}(\boldsymbol{\beta} \mathbf{1})$ \\
\hline var1 & 1.8718 & -0.7732 & 0.0005 & 0.4289 \\
var2 & 2.9444 & -1.9889 & 0.0041 & 0.0845 \\
var4 & 1.6094 & 0.3365 & 0.0010 & 0.7748 \\
var5 & 1.7047 & -0.0953 & 0.0017 & 0.9198 \\
var6 & 1.4351 & 0.9628 & 0.0039 & 0.4053 \\
var7 & 0.1823 & 3.0758 & 0.7633 & 0.0095 \\
var8 & 0.4556 & 0.0928 & 0.5907 & 0.1566 \\
var9 & -0.1340 & 0.0000 & 0.8611 & 0.1084 \\
var10 & 1.3863 & 0.0009 & 0.0024 & 0.9946 \\
var11 & 0.3322 & 0.0281 & 0.8519 & 0.4610 \\
var12 & 2.8904 & -1.0986 & 0.0639 & 0.4040 \\
var13 & 1.2528 & 18.3133 & 0.0068 & 0.9957 \\
var14 & 2.4423 & -1.7492 & 0.0009 & 0.0680 \\
var15 & 3.0681 & -0.4447 & 0.0914 & 0.4681 \\
var16 & 2.3665 & -0.0207 & 0.0432 & 0.5308 \\
var17 & -0.0104 & 0.0036 & 0.3539 \\
var18 & 2.2925 & 1.8326 & 0.3270 & 0.0723 \\
\hline
\end{tabular}

The probability that companies have recently made investments is significantly lower for loss-making companies from 0.950 to 0.722 . Furthermore, the probability of investing is significantly higher in limited companies, 0.963 against 0.546 for the other types. Finally, the probability of making investments is lower in companies where strategic choices are made only by the manager of the company, with a probability of 0.667 against 0.920 in other cases.

\section{Concluding remarks}

The research investigates companies in the chemical-plastic sector, focusing attention on corporate governance, investments, innovation, profitability and credit risk. The companies analyzed are based in the province of Salerno, in Italy. The research required a lot of data and information not available from the traditional sources used for this type of analysis. Therefore, we used a mixed survey method, using the data available from official sources (Chamber of Commerce and Revenue Agency) and the data obtained with a structured questionnaire submitted to the sample companies. To improve the efficiency of the estimates and ensure the representativeness of the sample, we used a stratified random method. The analysis showed that the sector is characterized by a large presence of micro-enterprises (61.9\%), small enterprises (20.1\%), and some large companies (4.1\%) active both on EU and international markets.

In most cases (69\%), the companies were founded by the current owner and consist of a limited number of partners, who decide the strategic and operational behavior of the company. In the sector, there are also family businesses, second and third-generation (19.9\%). In these companies, the decision-making process involves all family members. With reference to the critical success factors, quality and price represent the most important factors to compete on the market. Companies show a high propensity to make investments. These investments are mainly financed by reinvested profits and capital contributed by shareholders (72\%) and to a lesser extent by bank loans (26.1\%). The relationship with the banking system shows a medium-high criticality $(72.4 \%)$. The guarantees required, the overall costs and the time needed to obtain the loan are the most critical issues. The tight integration between ownership, control, and management often determines the subordination of investments to self-financing capacity.

The analysis of the relationships linking profitability, investments, innovation, and credit risk highlighted further specific elements. The results show a different credit risk depending on the geographical area of reference. In 
addition, companies that have invested in recent years have a significant probability of being profitable. Finally, innovations are significantly linked to the cost of labor. In the case of labor-intensive productions, the probability of innovating is less.

\section{References}

Amendola, A., Candila, V., Coppola, G., Coretto, P., Quattrocchi B., Sensini L., Storti G. (2013), Caratteristiche strutturali e funzionali delle imprese operanti in provincia di Salerno, Edizioni Scientifiche Italiane.

Bradburn, N.M., Sudman, S., Wansik, B. (2004), Asking Questions: The Definitive Guide to Questionnaire Design - For Market Research, Political Polls, and Social and Health Questionnaires, John Wiley and Sons.

Brasini, S., Freo, M., Tassinari, F., Tassinari, G. (2002), Statistica aziendale e analisi di mercato, Il Mulino, Bologna.

Cicchitelli, G., Herzel, A., Montanari, G.E. (1997), Il campionamento statistico, Il Mulino, Bologna.

Coda V. (1992), L'orientamento strategico di fondo, Utet, Torino.

Demsetz, H., Lehn K. (1985), The structure of corporate ownership: causes and consequences, Journal of Political Economy, 93 (6) (1985), pp. 1155-1177

Dobson, A.J., Barnett, A.G. (2008), An introduction to Generalized Linear Models, Third Edition, Chapman \& Hall/CRC Text in Statistical Science.

Fama, E.F., Jensen, M.C. (1983), Separation of ownership and control, The Journal of Law and Economics, 26 (2) (1983), pp. 301-325.

Frosini, B., Montinaro, M., Nicolini, G. (1994), Il campionamento da popolazioni finite, Il Mulino, Bologna.

Hall, G, Hutchinson, P, Michaelas, N. (2000), Industry effects on the determinants of unquoted SME's capital structure. International Journal of the Economics and Business 7(3): 297-312.

Helfert, E.A. (2000), Tecniques of Financial Analysis, Tenth Edition, Irwin Mc-Graw-Hill,

Hosmer, D.W., Lemeshow, S. (2000), Applied Logistic Regression, John Wiley and Sons.

Jensen, M.C., Meckling, W.H. (1976), Theory of the firm: Managerial behavior, agency costs and ownership structure, Journal of Financial Economics, 3 (4) (1976), pp. 305-360

Marchini I. (1995), Il governo della piccolaimpresa. Le basi delle conoscenze, Vol. I, Ins-Edit, Genova.

McConnell J.J., ServaesH. (1990), Additional evidence in equity ownership and corporate value

Journal of Financial Economic, 27, pp. 595-612

McCullagh P., Nelder, J.A. (1989), Generalized Linear Models, Second Edition, Chapman \&Hall/CRC.

Myers C. (1984), The capital structure puzzle, The Journal of Finance, 39 (3), pp. 574-592.

Myers, S.C., Majluf, N.S. (1984), Corporate financing and investment decisions when firms have information that investors do not have Journal of Financial Economics, 13 (2), pp. 187-221.

Pedersen, T., Thomsen S. (1997), European patterns of corporate ownership Journal of International Business Studies, 28 (4) (1997), pp. 759-778.

Porter M.E. (1980), Competitive Strategy, The Free Press, New York.

Porter M.E. (1985), Competitive Advantage, The Free Press, New York.

Ricci, R., Colombini, F. (1987), La finanza delle piccole e medie aziende, Giuffrè, Milano.

Sanchez, J.A., Sensini, L. (2017), Small Firms and Demand for Credit. Evidence from Europe, ICAFR, 237-262.

Sensini L., (2017), Capital Structure Determinants in Italian Sme's: An Empirical Study, ICAFR, 124-144.

Westhead, P., Howorth C. (2006), Ownership and management issues associated with family firm performance and company objectives, Family Business Review, 19 (4) (2006), pp. 301-316. 